\title{
Biopolitics, Populations, and the Growth of Genius
}

The present order of society ... is the great slaughter-house of genius and of mind.

-William Godwin, "Of the Sources of Genius"

A people is a detour of nature to get to six or seven great men. -Yes, and then to get around them. [Ein Volk ist der Umschweif der Natur, um zu sechs, sieben großen Männer zu kommen. -Ja, und um dann um sie herumzukommen.]

-Friedrich Nietzsche, Beyond Good and Evil

Michel Foucault's lectures from the I970s on the emergence of biopolitics and liberalism in the eighteenth century emphasize the key role played by the term "population" in those developments, and this trend suggests several important implications for literary criticism that focuses on this period. ${ }^{1}$ It did not take Foucault's work, of course, for literary critics to recognize the importance of the term "population" for literature of the eighteenth and nineteenth centuries, but earlier criticism tended to focus on the very late-eighteenth-century understanding of this term developed by Thomas Malthus. ${ }^{2}$ For Malthus, population was always potentially a problem and always connected to the twin specters of dwindling food supplies and surging sexual desire. Foucault, by contrast, stressed earlier understandings of the term, noting that for late-seventeenth- and eighteenthcentury authors, the "problem" of population was generally that of too few people rather than too many (a question of under- rather than overpopulation), that the key issue motivating discussion of populations was labor, and that emigration - which Malthus presented as simply a temporary or imaginary solution to the problem of overpopulation-was often understood as precisely what could resolve all kinds of population problems. Foucault also stressed the conceptual distinction between the population of a territory and the group of legal subjects within a realm. Where the latter concept presumed that the sovereign employed laws to prevent or encourage various behaviors, a population was understood as a collection of relatively recalcitrant bodies that tended to follow their own movements, no matter what laws were enacted; as a consequence, the legislator governed best when he or she found ways of channeling these existing movements. 
For Foucault, the concept of population underpinned the emergence of both liberalism, which presumed that one governed best when individuals could determine, so far as possible, their own courses of action, and biopolitics, which involved gathering data about the biological aspects of a population (for example, "health, hygiene, birthrate, life expectancy, [and] race") so that one could then alter some of those dynamics. ${ }^{3}$

This chapter builds upon Foucault's work by considering the implications of eighteenth-century approaches to population for our understanding ofliterary texts. However, I focus on the link between eighteenth-century population thinking and the identification of the purportedly rare quality of genius to emphasize that biopolitics is not restricted solely to those clearly biological aspects of collective life, such as health, hygiene, and birthrate, that Foucault stressed. My starting point is William Petty's intriguing claim in Another Essay in Political Arithmetick (I683) that among the virtues of increasing the population of a territory is a potential increase in the "Arts of Delight and Ornament," for, Petty claims, "it is more likely that one Ingenious Curious Man may rather be found out amongst 4 millions than 400 persons." Petty, a member of the Royal Society and founder of "political arithmetick," is an important figure in the history of economics, the history of statistics, and recent discussions of the history of population theory, primarily because of his interest in creating categories for counting and measuring people within a territory. Yet Petty's interest in population has tended to be read as a homogenizing enterprise: though political arithmetic distinguished between kinds of people, it often seemed committed to erasing differences between individual bodies in favor of abstract, shared human capacities, such as the capacity to labor. What Petty's comment about genius underscores, though, is another way that seventeenth- and eighteenth-century authors thought about both population and the techniques by which legislators could know and channel its resources. Rather than restricting political arithmeticians to broad categories (for example, kinds of laborers), the concept of population also encouraged Petty to consider rare instances of something virtuous - not simply the Ingenious Man, not simply the Curious Man, but the Ingenious Curious Man-and to consider how, through regulation, one might increase the number of such individuals.

Petty's comment illuminates an important series of links between three eighteenth-century topics: genius, population, and "literature" (a term that, by around the end of the eighteenth century, had come to refer solely to "elevated" forms of fictional writing). In schematic form, my argument is the following. The tentative link that Petty established between genius 
and population was consolidated neither in political arithmetic nor in its successor, political economy, but rather in two more "literary" arenas: mid-eighteenth-century debates about the nature of genius and mid- to late-eighteenth-century poetry that reflected on how geniuses might be overlooked or lost. These discourses helped transform the link between genius and population from an abstract connection to a topic of vital concern. Mid-eighteenth-century discourses on genius fleshed out Petty's aspiration for a political arithmetical approach to genius by emphasizing forms of regulation purportedly capable of increasing the number of geniuses in British territory. Poetry, for its part, illuminated Petty's aspiration of maximizing genius by surrounding this positive goal with two "negative" possibilities, or what I will call biopolitical forms of concern about what might result were genius not to be regulated. First was the worry, exemplified in Thomas Gray's Elegy Written in a Country Churchyard (I75I), that, in a large population without sufficient forms of institutional discovery and nurturing, potential geniuses would be lost. The second kind of worry, exemplified by William Wordsworth's I80o Preface to Lyrical Ballads and the "Arab Dream" section of The Prelude, was that, in a large population with its own dynamics of interest and entertainment, a genius once glorious, such as Milton, could be forgotten. Both kinds of worry, I suggest, were key to the emergence of population as an effective biopolitical concept and provided means for transforming the abstract possibility of maximizing the incidence of a quality (genius) into a pressing concern for individuals. At the same time, both worries - that of unseen literary potential and that of misplaced literary value - can only be problems (that is, can only become legible and insistent sources of concern) from the viewpoint of population thinking. In the final part of my argument, I contend that the modern, restricted notion of "literature"-literature understood as especially valuable instances of imaginative writing, primarily in the genres of poetry and drama-emerged as the concept and institution that fully sutures Petty's biopolitical hope of maximizing genius with Gray's and Wordsworth's (equally biopolitical) worries about losing genius.

As some readers may already have noted, my literary examples parallel those employed by John Guillory in his well-known sociological account of the emergence of the modern concept of literature. ${ }^{5}$ This is not a coincidence, for in addition to expanding our understanding of biopolitics beyond those clearly biological elements upon which Foucault focused, I also hope to clarify important differences between sociological and biopolitical readings of eighteenth-century literary culture. Guillory focused on 
Gray and Wordsworth precisely because these two authors had become part of the "canon" within the schooling systems of the United Kingdom (and its colonial possessions) and the United States. His powerful and nuanced reading of the reasons why Gray and Wordsworth became part of the canon (which depended in part on their contributions to the development of our modern concept of literature) provides a helpful contrast to my biopolitical reading of this same development, for I stress a different understanding of the affective work of literary texts than that outlined by Guillory: Rather than functioning solely as what Guillory describes as points of "rest" in the midst of general social competition, literary texts also functioned as instigators of those emotions and affects essential to the operation of biopolitics.

\section{Political Arithmetic and the Increase of Genius}

"Political Arithmetick" was the name William Petty gave, in the late seventeenth century, to what he hoped would be a new science that, by counting and measuring people and things within a country - that is, by the use of "Number, Weight, or Measure"-would increase the wealth and military strength of the nation. This new science was arithmetical in the sense that it would allow legislators to answer conclusively, in the manner of arithmetical demonstrations, quantitative questions, such as whether "the Rents of lands [in the kingdom] are generally fall'n," whether "there is a great Scarcity both of Gold and Silver," and whether "the land is underpeopled." Unequivocal demonstrations of the answers to such questions would not only displace unfounded opinions upon which legislators might otherwise base political decisions but would also encourage legislators to consider how best to maximize desired aspects of a specific country. Petty's interest in counting people and things was fundamentally oriented toward identifying limits - that is, maxima and minima of qualities such as national wealth or the amount of daily food a laborer needed to survive-and locating those points in the social field at which pressure could be applied in order to encourage movement of some quality toward the desired maximum or minimum. Petty insisted that maximizing qualities such as wealth or military strength was not simply a matter of having more people or land, for even "a small Country [with] few People" can, if it sufficiently exploits "its Situation, Trade, and Policy ... be equivalent in Wealth and Strength, to a far greater People and Territory." 7

As twentieth-century commentators have noted, though Petty's new science of political arithmetic attracted followers and commentators, it 
remained more of an aspirational than actual science. ${ }^{8}$ Petty, and subsequent advocates of political arithmetic such as John Graunt, provided legislators with numbers about all kinds of things, such as the historical and projected future population growth for England, London, and the entire globe and the basic cost of keeping alive a laborer (seven pounds per annum, according to Petty). ${ }^{9}$ Yet contemporary legislators seemed neither particularly interested in basing policy on this data nor in establishing the kinds of data collection systems that Petty and his followers stressed were necessary for the development of this new science. Political arithmetic thus remained during the eighteenth century a well-known potential science, but its approach to governing by numbers was not put into practice until the nineteenth and twentieth centuries.

Yet if political arithmetic failed to materialize as a science of governing in the way that Petty and his followers had hoped, it nevertheless fundamentally transformed the intellectual landscape around several key concepts, especially the connection between "population" and "people." his seventeenth-century essay "Of Seditions and Troubles," Francis Bacon had urged legislators to see the state of "the population" as a key factor in encouraging or hindering political upheaval, and he had stressed that "the Population" is not "to be reckoned only by number; for a smaller number that spend more, and earn less, do wear out an Estate sooner than a greater number that live lower, and gather more." "11 Though Petty and Graunt tended to use terms such as "the People" or "the Nation" rather than "population," political arithmetic, even just as aspiration, helped eighteenthcentury authors begin to understand what it would mean to reckon population not as a single number but as a complex collection of bodies and desires that contained numerous potential maxima and minima of qualities such as wealth, subsistence, and military power.

It is in this context that Petty's claims about genius take on their real significance. Political arithmetic allowed eighteenth-century authors to understand population as, among other things, that within which legislators could maximize desired qualities and minimize undesirable qualities. In some of Petty's examples, maximizing a value such as wealth or military power depended on determining the absolute minimum of something that everyone needs, such as food, or something that the vast majority of people should do, such as labor. But Petty's example of the "Ingenious Curious Man" underscores that political arithmetic was also interested in qualities possessed by only a few individuals. Petty discussed the maximization of geniuses in the context of a political arithmetical analysis of London, in which he proposed "two Imaginary states" of London, one in which the 
city was seven times its current size and one in which it was one-seventh its current size. ${ }^{12}$ Petty analyzed these two states according to a number of criteria, such as defensibility of the city from foreign attackers; prevention of "intestine Commotions of Parties and Factions; "Gain by Foraign [sic] Commerce"; and "Husbandry, Manufacture, and . . Arts of Delight and Ornament." 13 Petty concluded that since the "Arts of Delight and Ornament" are "best promoted by the greatest number of Emulators," and since "it is more likely that one Ingenious Curious Man may be found out amongst 4 millions than 400 persons," the more populous of London's imaginary states would best serve that goal. Though the maximization of genius was not a capacity to which Petty returned in his texts on political arithmetic, this aspiration was nevertheless fully consonant with-and arguably a necessary implication of-his understanding of population as a collection of individuals within which qualities can be maximized and minimized.

Though Petty's assumption that "it is more likely that one Ingenious Curious Man may be found out amongst 4 millions than 400 persons" may seem commonsensical, not all eighteenth-century authors agreed. In his Letter to D'Alembert on the Theater (I758), for example, Jean-Jacques Rousseau-an author obsessed with the economic dimensions of modern life and who likely read Petty_claimed something quite different..$^{14}$ Rousseau's open letter was intended to contest Jean d'Alembert's glowing description of the institution of the theater and his suggestion that a theater should be established in Geneva. In earlier publications such as Discourse on the Sciences and Arts (I750) and Discourse on the Origin and Basis of Inequality among Men (I754), Rousseau had already written critically about the modern increase of genius in the arts and sciences and established his antagonism to both theater and spectacle-based relationships of modern urban life. In his Letter to D'Alembert, he sought to convince his readers that the institutions of small-town life were not stultifying but instead would, if fully embraced, result in an increase in genius:

In a little town, proportionately less activity is unquestionably to be found than in a capital, because the passions are less intense and the needs less pressing, but more original spirits, more inventive industry, more really new things are found there because the People are less imitative; having fewer models, each draws more from himself and puts more of his own in everything he does; because the human mind, less spread out, less drowned in vulgar opinions, elaborates itself and ferments better in tranquil solitude; because, in seeing less, more is imagined; finally, because less pressed for time, there is more leisure to extend and digest one's ideas. ${ }^{15}$ 
While Rousseau also dealt with the question of genius and innovation from the perspective of population, his understanding of the connection between genius and imitation led him to conclude that the relevant "incubator" population for genius could be a small town, rather than a very large city. For Rousseau, what allowed genius to emerge from a population was not the size of the latter but rather the kinds of social relations it encouraged.

Though Petty's reflections on political arithmetic isolated the maximization of genius as a potential goal for future legislators, they also raised several questions. For example, was population increase the key to producing more genius, or were social institutions of the sort described by Rousseau necessary both to identify and cultivate genius? If population expansion was indeed necessary for an increase in the number of geniuses, what other forces, social or otherwise, might hinder its actual increase? Though these questions might be addressed in part by counting and numbers, they were more fundamentally about models of populations and the relationship between populations and social institutions such as those described by Rousseau. As I note in the next two sections, though some of these considerations were taken up obliquely in late-eighteenth-century sciences such as political economy, the implications of population thinking for the maximization of genius were more thoroughly investigated in philosophical and literary reflections on genius itself.

\section{Political Arithmetic, Political Economy, and Genius}

Though most elements of Petty's political arithmetic, such as national censuses, remained aspirations rather than implemented technologies during the eighteenth century, his "liberal" approach to social order nevertheless established a template that was subsequently taken up more successfully by the new mid-eighteenth-century science of political economy. ${ }^{16}$ Petty's approach was liberal in that he understood the legislator not as a sovereign who possessed the capacity to control the behavior of his subjects via legislation but rather as an observer-regulator who could, through the new science of political arithmetic, locate and then harness existing "natural" forms of behavior that evade the reach of law. Foucault captures this in his description of liberalism as fundamentally oriented toward truth rather than justice: for liberals, legislators must first focus on the truth of how an institution, such as "the market," functions naturally, rather than seeking to intervene in the operation of this natural institution in the name of justice (by, for example, establishing a "just" price for wheat). ${ }^{17}$ Foucault's account explains Petty's desire for political arithmetic; this numerical 
dimension indexed Petty's effort to shift the activity of the legislator from justice and right and toward truth and knowledge. Foucault's account also helps us understand better Petty's understanding of population as a collective characterized by autonomous forms of natural movement, rather than as simply a collection of legal subjects. As authors such as David Hume, James Steuart, and Adam Smith subsequently created what would become known as political economy, they fully embraced this liberal approach pioneered by Petty, even if they did not always adopt Petty's particular techniques. ${ }^{18}$

Perhaps counterintuitively, Petty's liberalism also established the basic framework for the mid-eighteenth-century explosion of texts on genius. In precisely the same period that Hume, Smith, and Steuart published their texts on the wealth of nations and political economy, authors such as William Sharpe, Alexander Gerard, William Duff, and Edward Young published extended "dissertations," "essays," and "conjectures" on genius. This coincidence has been the subject of an important debate among literary critics who have sought to shift discussion of mid-century texts on genius from an exclusively aesthetic discourse to one that acknowledges the dependence of aesthetic categories, such as genius, on class-based ideologies. The key point of debate has been whether, as Martha Woodmansee and Mark Rose have argued, the discourse of genius was part of political economy or whether, as Zeynep Tenger and Paul Trolander have argued, the discourse of genius was instead a rival to political economy: that is, an alternative understanding of how to generate the "wealth of nations." ${ }^{19}$ Yet arguably lost in this focus on the ideological dimensions of the genius debate are its liberal and biopolitical dimensions. Authors such as Sharpe, Gerard, Duff, and Young sought to determine the truth of genius - its various modes, its relationship to our mental faculties, and its relationship to imitation - so that the incidence of genius could be increased. From this perspective, the ideological convergence or tension between political economy and debates about genius is less important than the fact that both develop within the liberal, biopolitical framework initiated by Petty.

The desire to maximize genius within a national territory was explicit in most mid-century British texts on "original genius." In A Dissertation upon Genius (I755), Sharpe contended that genius was not implanted by nature but was the result of circumstance and education; as a consequence, "multitudes of Geniuses are scatter'd" not randomly, as would be the case if nature implanted genius in individuals, but instead grouped in areas where "opportunity, example, and encouragement concur." 20 
Sharpe contended that understanding how genius emerged enabled a polity to increase its number of geniuses; by the same token, failing to take these forces into account would be a loss not just for certain individuals but for the country as a whole. ${ }^{21}$ Though most other commentators argued that genius was a natural endowment, rather than the result of education, they nevertheless stressed the possibility of regulating its emergence and expression. Gerard, for example, began An Essay on Genius (1774) with the claim that genius is "the grand instrument of all investigation," whether scientific or artistic, and that understanding its nature would enable a "regular method of invention" (and that without such a method, "useful discoveries must continue to be made, as they have generally been made hitherto, merely by chance"). ${ }^{22}$ In similar fashion, Edward Young suggested in Conjectures on Original Composition (I759) that though the "modern powers [of genius] are equal" to those in earlier times, "modern performance in general is deplorably short" as a consequence of the fact that earlier ages provided more effective governmental "encouragement" than did the present age. ${ }^{23}$ For these authors, genius was a topic directly related to the national capacity for scientific and artistic innovation and was hence something that could, and should, be regulated to whatever extent possible.

Understanding mid-century discussions of genius as oriented toward the maximization of this capacity emphasizes that debates about whether genius was natural or acquired were first and foremost efforts to locate those points at which regulatory technologies could be most efficaciously introduced. For example, Sharpe's explicitly Lockean claim that each of us is born as an equivalently "blank paper" 24 and that genius must therefore be the result of education and circumstance suggested that educational institutions were key sites at which genius could be increased; it further implied that the educational formula for enabling genius, if discovered, should be applied universally. Young, by contrast, claimed that nature "brings us into the world all Originals: No two faces, no two minds, are just alike; but all bear Nature's evident mark of Separation on them." 25 However, "that medling Ape Imitation . . blots out nature's mark of Separation, cancels her kind intention, destroys all Individuality" (42), which would likely militate against a uniform system of schooling. Sharpe's and Young's differences with respect to the origin of genius-is it innate or acquired?-are more fundamentally differences about how and where best to regulate those educational institutions through which children pass, so as to increase the number of geniuses. ${ }^{26}$ 
Focusing on regulation as a key desideratum of discussions of genius allows us to reconsider the plant metaphor so central to eighteenth-century discussions of genius. Joseph Addison had established the topos of "vegetable" genius in his famous Spectator essay (\#I60, September 3, I7II), in which he distinguished between two kinds of "great geniuses," those who write without following rules and those who write within the constraints of rules. "The genius in both these classes of authors may be equally great, but shows itself after a different manner," Addison wrote.

In the first [the genius who does not follow rules] it is like a rich soil in a happy climate, that produces a whole wilderness of noble plants rising in a thousand beautiful landscapes without any certain order or regularity; in the other [the genius who follows rules] it is the same rich soil, under the same happy climate, that has been laid out in walks and parterres, and cut into shape and beauty by the skill of the gardener. ${ }^{27}$

For Addison, genius is simultaneously a medium (a rich soil) and an agent (a gardener) who can decide whether to manipulate that soil and its productions; this manipulation or its lack then alters the distribution and nature of the productions of genius. Though Addison suggested that one kind of great genius arises without the genius-gardener having to cultivate his rich soil, the second kind of genius - which includes authors such as Plato, Aristotle, Virgil, Tully, Milton, and Bacon-requires the geniusgardener to self-regulate his own genius-soil. Addison's proposal that one kind of genius requires self-regulation hints at the question of what more general regulatory measures, of the sort considered by Sharpe and Young, might encourage such self-regulation.

Addison's vegetable image was taken up by Young, who contended that an "original" composition of genius "may be said to be of a vegetable nature; it rises spontaneously from the vital root of Genius; it grows, it is not made." 28 In his classic account of Young's metaphor, M. H. Abrams emphasized autonomy, reading Young as stressing that just as plants grow on their own, so too does the product of genius. ${ }^{29}$ Yet one senses that Young was far more interested in plants that can be cultivated than those that grow wild, since Young asserted that

an Evocation of vegetable fruits depends on rain, air, and sun; and Evocation of the fruits of Genius no less depends on Externals. What a marvellous crop bore it in Greece, and Rome? And what a marvellous sunshine did it there enjoy? What encouragement from the nature of their governments, and the spirit of their people? ${ }^{30}$ 
Pace Abrams, Young stressed the vegetable nature of genius not primarily to depict its freedom from human meddling but to underscore its capacity for management and regulation, that is, to be encouraged and directed by the "sunshine" of government and the spirit of a people. Humans cannot produce plants ex nihilo, but they can facilitate the vitality of plants by managing the media, such as soil, warmth, and exposure to light, that enable plants to grow. In the same way, Young suggested that, though genius emerges from sources unknown, once it has come into being, at least some kinds of genius can be facilitated by managing the cultural "media" within which humans grow and thrive.

Though Tenger and Trolander are in one sense correct that the discourses of genius and political economy provided competing explanations for the phenomena of national wealth increase and technological progress, from a wider perspective both discourses cooperated in the sense that both encouraged a liberal imagination. This liberal imagination, or perspective, sought to locate and demarcate the realms in which "nature" expressed itself in human relations, to determine the truth of nature's operations in those realms, and to devise forms of regulation that could more successfully exploit those natural dynamics. For both discourses, the operations of nature in social relations were intimately linked to differences among individuals, though each discourse understood this link differently. In the case of political economy, the diversity of individuals" "interests" served as the natural force that enabled the market, the division of labor, and wealth, and so the legislator should orient his minimal regulatory activities toward a careful balancing of interests. ${ }^{31}$ In the discourse of genius, the diversity of "potential" and the diversity of different kinds of genius were instead the concepts around which one could locate nature's entry into the field of social relations. Commentators focused their attention on those institutions such as schools, social groupings, or government patronage that purportedly translated potential genius into actual expression and hence increased the amount and diversity of genius.

\section{Poetry, Genius, and Worry: Gray's Elegy}

Interest in maximizing genius by harnessing differences among individuals was pursued not only in texts about genius but also in works of poetic genius (or, at any rate, works by authors hoping to be perceived as geniuses by peers and subsequent generations). Where essays, dissertations, and conjectures sought to produce knowledge about genius in order to locate possible sites of regulation, poetic texts strengthened the biopolitical project 
of maximizing genius by linking Petty's positive ideal, the increase of genius, to negative alternatives, bodied forth in figures of unharnessed value. These negative possibilities clarified both that genius maximization would not necessarily happen of its own accord and that the consequences of allowing geniuses to remain undiscovered were dire. Thomas Gray's Elegy Written in a Country Churchyard (I75I) expressed one of these negative alternatives in the worry that a polity might fail to locate potential geniuses - that is, that would-be Miltons would remain mute and inglorious - and then surrounded that image of lost potential with other images of undiscovered or unappreciated value.

Among the many peculiarities of Gray's Elegy is its ambivalence concerning the condition of poverty that it presents as that which mutes potential Miltons. The Elegy's narrator, viewing a humble country churchyard, rues the fact that only "Chill Penury" prevented those rustic poor whose hearts were "once pregnant with celestial Fire," or whose "Hands . . the Reins of Empire might have sway'd," or who might have "wak'd to Extacy the living Lyre," from attaining the "Knowledge" that would have turned potential into actual achievements. ${ }^{32}$ Yet as William Empson famously noted, the Elegy also suggests that poverty is natural and cannot be ameliorated, which makes this loss of genius seem irremediable. Figuring the loss of potential among the poor by means of natural objects-a "Gem" hidden in the "dark, unfathom'd Caves of Ocean" or a flower born to "blush unseen" in the desert $(8 ; 11.53-56)$ - the social causes of poverty become part of the natural order. "By comparing the social arrangement to Nature," Empson wrote, Gray "makes it seem inevitable, which it was not, and gives it a dignity which was undeserved." 33 This sense of inevitability is further consolidated in both the elegiac mood of the poem and its setting in a churchyard: "The tone of melancholy claims that the poet understands the considerations opposed to aristocracy, though he judges against them; the truism of the reflections in the churchyard, the universality and impersonality this gives to the style, claims as if by comparison that we ought to accept the injustice of society as we do the inevitability of death" (4). Empson makes these points in support of his more general claim that the poem documents an England that has no "scholarship system or carrière ouverte aux talents" capable of locating and unearthing these hidden gems of potential poetry among the poor (4).

Where Empson interprets the Elegy's ambivalence about poetry and the loss of potential genius through a moral lens-he suggests that this ambivalence is the source of many readers' irritation with the poem's "complacence" and what they feel is a "cheat in the implied politics" 
(5)-John Guillory develops a more ambitious account, finding in the poem's ambivalence one of several instances of "rest," which, in his reading, enabled the poem to ensure its central place in an emergent canon of vernacular literature. ${ }^{34}$ Guillory's reading of the Elegy is extraordinary and compelling in large part because he illuminates the extent to which the poem carefully suspended itself between numerous eighteenth-century cultural developments: For example, the poem alludes to the refinements of the classical poetic heritage while remaining firmly vernacular in its own language, and it serves as a sort of commonplace of poetic allusions while at the same time appealing to the private retreat of the pastoral. For Guillory, then, the poem's ambivalence about poverty is just one of the many ways - or rather, it is the synthesis of the multiple ways - that the Elegy offers its readers a "unique place of rest," or suspension, in a rapidly transforming society. ${ }^{35}$ For Guillory, what may seem like the poem's equivocating refusal to make a strong claim about the relationship between poverty and lost genius - is poverty a condition one should seek to ameliorate in order to maximize genius, or should one instead simply accept poverty, and its elimination of would-be geniuses, as natural?-is better understood as a canny lessening of tension, captured in Gray's own deflationary image of a "Tribute of a Sigh" (9;1.80), that allowed readers to claim the cultural capital of appreciating vernacular poetry without having to choose between these disjunctive positions on poverty.

Yet one wonders if rest is the best term to describe the effects of the poem's lament over the loss of potential. Empson and Guillory are no doubt correct that Gray's poem calls forth no more than virtual readerly tears (and certainly no kind of concrete ameliorative action) for those "mute, inglorious Miltons" who perish because of poverty. However, the indefinite nature of the subject of the Elegy - the poem is set in an unspecified country churchyard and is about an equally abstract category of gifted poorencourages a quite modern kind of imaginative activity, namely, the imagination of populations and the ways that mute inglorious Miltons among them could be given voice and glory. From this perspective, the poem does not ask its readers to determine whether poverty is remediable but rather employs chill penury as a vector that allows readers to imagine the population of a national territory and how the members of that population could each be assayed for a given quality. Precisely because poverty is widespread-because its victims cannot be restricted to those buried in this graveyard, wherever this graveyard might be-the poem authorizes and encourages the reader to imagine this untapped potential of possible Miltons as distributed throughout the geographic and linguistic territory of 
Britain. This in turn suggests that identifying and bringing to voice otherwise mute Miltons will require the discovery or creation of a "surface" through which all members of the population would pass and that can be used to test for a given capacity (in this case, potential genius); this surface is the key element of a system that can then locate those few (Petty's one in 4 million) who are indeed potential rivals of Milton. ${ }^{36}$ The unintended irony of Empson's reading is that his almost dismissive suggestion that the Elegy reveals the pathos of a polity that lacks a "scholarship system or carrière ouverte aux talents" exemplifies precisely this kind of imaginative activity. In proposing a system that could identify talent wherever it might arise, Empson responds to the form of worry that the poem encourages by imagining populations and the institutions that might identify differences among the members of a population.

A surface capable of encompassing a population and identifying talent among individuals could take forms other than Empson's proposed scholarship system. Such a surface could take the form of aristocratic patronage of "peasant poets" or widespread literacy plus access to a literary market. In the early twentieth century, W. E. B. Du Bois imagined historically black colleges and universities as such a surface capable of locating the "talented tenth" who could "guide the Mass away from the contamination and death of the Worst, in their own and other races," while Virginia Woolf suggested that the means for giving voice to an otherwise "mute and inglorious Jane Austen" was five hundred pounds a year and a room of her own. ${ }^{37}$ For other authors, only the complete transformation of social relations would enable hidden value to be uncovered. P. B. Shelley, for example, imagined in the first scene of act IV of his drama Prometheus Unbound (I820) "vast beams" of light that "pierce the dark soil, and as they pierce and pass, / Make bare the secrets of the earth's deep heart," secrets that include not only "valueless stones, and unimagined gems," but also past human achievements now buried and otherwise lost. ${ }^{38}$

Empson's solution to the problem posed by the poem emphasizes that the transcendence implicit in the religious aspects of the Elegy operates in service of a more secular, biopolitical form of longing and redemption. The poem's narrator echoes the traditional claim that death is the great equalizer - the "Paths of Glory," just like the paths of the unknown villagers buried in the country churchyard, all "lead but to the Grave" ( $7 ; 1$. 36) - and stresses that the memorials left by the rich, such as a "storied Urn, or animated Bust" (7; 1. 4I) cannot restore life to those who were once famous but are now dead. That is, the social differences that seem so 
important to the living are of no consequence in our final destination, for we all pass into the afterlife through the common surface of "silent Dust" ( $7 ; 1$. 43). Yet the Elegy is not satisfied with this claim of afterlife equality, for it follows these accounts of converging paths and useless memorials with the poem's key images of unrealized potential (the heart pregnant with celestial fire, the submerged gem, the unseen desert flower). Rather than orienting readers toward imagination of a world beyond ours, the Elegy's emphasis on our common condition instead turns us toward an earthly future in which potential that went unseen in the past can be redeemed, and in a sense even resurrected, by locating ways, such as Empson's scholarship system, that can give voice to otherwise mute and inglorious Miltons. To put this another way, the Elegy's images of individual death lead us to discern a more primal vital body — what Cleanth Brooks described in his reading of the poem as our "common humanity" but that, following Foucault, I am more tempted to call the multiple body of the population-that continues to generate genius in every generation. ${ }^{39}$

While Gray's Elegy may indeed have provided readers with a point of rest within what Guillory calls "the agon of social mobility," it also encouraged a form of intense biopolitical imaginative activity oriented toward the discovery or invention of surfaces that could subtend entire populations in order to identify and develop qualities of interest, such as Milton-like genius. The Elegy did not simply provide its bourgeois readers with cultural capital by letting them off the hook (that is, facilitating a form of social advancement that feels like rest); it also, and arguably more fundamentally, encouraged biopolitical forms of worry (how to locate would-be geniuses) that in turn encouraged the imagination and eventual implementation of solutions such as the scholarship system that Empson extolled.

\section{Biopolitics, Worries, and Smallpox Inoculation}

I will return below to the second form of biopolitical worry that emerged, a few decades later, from the crucible of these debates on genius. First, though, I want to underscore the extent to which forms of worry analogous to those that I have analyzed in the context of debates about genius were also central to eighteenth-century projects such as smallpox inoculation, which conform more closely to those campaigns and apparatuses that Foucault had in mind with (and many readers will likely understand by) the term "biopolitics." While smallpox inoculation in Britain in the early part of the eighteenth century was restricted primarily to the 
aristocratic and middle classes, mid-eighteenth-century advocates of this medical practice imagined and began to develop institutions, such as the Foundling Hospital and the Smallpox and Inoculation Hospital, intended to inoculate those who lacked the means to pay for treatment (that is, the poor), with the eventual goal of inoculating the entire population. ${ }^{40}$ Eighteenth-century advocates of smallpox inoculation did not support this goal of population-wide inoculation with our contemporary concept of "herd immunity" but instead sought to garner support for their efforts by means of negative images of stalled commerce and difficult daily life for the middling and upper classes.

An especially important site for the generation of biopolitical images of worry were the annual sermons commemorating the 1746 founding of Middlesex Hospital for the Small-Pox and Inoculation. ${ }^{41}$ In addition to providing yearly accounts of the number of successful inoculations (and the increasingly minuscule percentage of deaths from inoculation), the published versions of these sermons clarified the aspirations behind the desire to expand smallpox inoculation. These aspirations often had to be inferred as the inverse of worries about what would happen should the poor not be inoculated against smallpox. In I753, for example, Isaac Maddox asserted that the key problem with smallpox was that it caused "Cessation of Trade and Business." ${ }^{2} 2$ This claim was repeated by John Green a decade later, and he expanded on why this was the case, contending that since "men cannot flee from place to place, to avoid the danger of infection," epidemics ensure that "multitudes will soon be reduced to poverty, manufactures will be stopt, [and] commerce will stand still," among other evils. ${ }^{43}$ In his 1760 sermon, Samuel Squire commanded his listeners to "See that multitude of industrious poor thronging in every quarter of this immense theatre of commerce, business, and action! See them distributing themselves through all the laborious offices of society!" but also encouraged his audience to imagine this scene of pacific commerce disrupted by the outbreak of smallpox. ${ }^{44}$ Five years later, Richard Eyre suggested that, without the smallpox hospital and inoculation, his listeners' "Prosperity" and

success ... might not otherwise have been obtained, with so much ease, and readiness, had they been debarred, or affrightened, from a Due and Regular pursuit, of the business, of their several callings, either, from their own, or their friends apprehension, (for them,) of concurring the danger, of so Precarious a distemper; in consequence of a diligent, and a necessary 
attendance, upon each respective branch, of publick trade, or commerce, which could not but expose them to such hazard! $!^{45}$

This same theme was again stressed by Brownlow North in his 1773 sermon, in which he asserted that smallpox "impends on every village, on every seat of manufacture and trade, on every useful assemblage of men whatever, whose extreme poverty, or unremitted industry, has prevented their timely preparation, by the easy method established in this hospital."46 These advocates saw smallpox inoculation as a practice that would, ideally, be extended to all individuals within the national territory, thereby guaranteeing security of health and hence ensuring the uninterrupted commerce that many eighteenth-century authors seem to have understood as the final cause of health.

Though smallpox and genius were understood by eighteenth-century commentators as quite different kinds of qualities-for most authors, only a few individuals could be geniuses, while smallpox could affect everyoneboth inspired reflections about how populations might be regulated in order to maximize or minimize their incidence. These reflections were enabled in both discourses by negative images of worry and concern: in the case of the genius debates, what would happen if too many geniuses were left undiscovered; in the case of debates about smallpox inoculation, what would occur if smallpox were to affect too many people. This correspondence between reflections on genius and more obviously biopolitical measures such as the eighteenth-century British smallpox campaigns thus sheds light on an aspect of biopolitics not often stressed in accounts of its development, namely, the extent to which biopolitical technologies require the development of images of negative and positive population possibilities. In the case of health-oriented measures such as smallpox campaigns, the positive pole (embodied in figures of health, political stability, and uninhibited commerce) and the negative pole (figured in images of death, political instability, and commercial stasis) were developed in medical pamphlets and religious sermons. In the case of genius, the positive consequence of maximizing this quality - namely, the progress of commerce and the arts - was developed early in political arithmetic and subsequently in a sui generis discourse on the nature of genius. Yet this positive biopolitical pole could not exist independently; for its positivity to shine forth, it had to be counterposed to what would feel like an equivalent form of loss. The consequences of losing geniuses remained implicit in Petty's text and in subsequent treatises on genius but were developed explicitly in poetry, such 
as the figures of unrealized potential in Gray's Elegy (mute inglorious Miltons, submerged gems, unseen flowers) and the effort of the poem to make these feel like British losses.

\section{Worry, Preservation, and the Emergence of "Literature"}

Near the end of the eighteenth century, commentators on genius also began to worry that, in addition to the form of loss lamented in Gray's Elegy-potential genius that did not become actual-geniuses that had been properly valued might also be lost. Young had touched briefly on this possibility in the mid-eighteenth century, noting that many ancient authors whom we value as geniuses were simply imitators of earlier geniuses now lost to us: "It is said, that most of the Latin classics, and all the Greek, except, perhaps, Homer, Pindar, and Anacreon, are in the number of Imitators, yet receive our highest applause ... [because] the works they imitated, few excepted, are lost." ${ }^{\prime 47}$ Young concluded, however, that the "perpetuating power" of the printing press rendered such losses less likely in the present, and there was thus relatively little danger that the works of a modern genius such as Milton could disappear.

For late-eighteenth-century commentators such as William Wordsworth, though, the printing press was not necessarily Milton's salvation but rather that which threatened his works. Wordsworth saw a conflict between cultural attention and memory, for the printing press's perpetuating power multiplied not only copies of Milton's works of genius but also mediocre novels, which successfully competed with Milton for public attention. Wordsworth worried in the 1800 Preface to Lyrical Ballads that, as a consequence, the capacity for appreciating the works of past geniuses was disappearing:

For a multitude of causes unknown to former times are now acting with a combined force to blunt the discriminating powers of the mind, and unfitting it for all voluntary exertion to reduce it to a state of almost savage torpor. The most effective of these causes are the great national events which are daily taking place, and the encreasing accumulation of men in cities, where the uniformity of their occupations produces a craving for extraordinary incident which the rapid communication of intelligence hourly gratifies. To this tendency of life and manners the literature and theatrical exhibitions of the country have conformed themselves. The invaluable works of our elder writers, I had almost said the works of Shakespeare and Milton, are 
driven into neglect by frantic novels, sickly and stupid German Tragedies, and deluges of idle and extravagant stories in verse. ${ }^{48}$

For Wordsworth, the printing press was as much a curse as a saving power, for its indifference to the quality of its productions enabled works of genius to be drowned in a deluge of popular literature.

Guillory seems to me correct when he suggests that the modern concept of "literature" requires Wordsworth's apocalyptic image of culturally created deluge and loss. The well-researched narrowing of the concept of literature at the end of the eighteenth century involved both the restriction of the term to include only imaginative works (rather than, as had been the case earlier, also historical and philosophical works) and a subsequent further belt tightening that left only poetry, novels, and plays. ${ }^{49}$ Guillory argues that this restricted concept of literature encouraged belief in a purported distinction of quality between "the works of Shakespeare and Milton," on the one hand, and a deluge of popular literary works written in the vernacular, on the other. Yet as Guillory notes, this purported difference in quality could no longer be marked in any clear way, since the difference was not that of, for example, works composed in classical languages and those composed in the vernacular. In this sense, "Wordsworth can conjure up an apocalyptic scenario in which the words of Milton and Shakespeare are swallowed up in the sea of popular writing . . . [only] because the distinction between serious and popular genres produces no corresponding linguistic differentiation within the reading public." ${ }^{50}$ Guillory's larger point is that this new concept of literature, like its canonized exemplar, Gray's Elegy, served the interests of a rising bourgeoisie, who desired the cultural capital associated with the lettered aristocracy but were suspicious of the classical education of the latter. Or, as Guillory puts it, "the fact of increased upward mobility is at once the premise of 'bourgeois ideology' - that anyone can succeed-and its prime source of social anxiety. Hence the continuous appropriation by the bourgeoisie of aristocratic caste traits, precisely in order to reinforce and stabilize a class structure founded upon a necessary degree of instability or fluidity" (93). The new concept of literature promoted the aspirations of the bourgeoisie for upward mobility by suggesting that they too now possessed what had previously been an exclusively aristocratic canon of works. At the same time, though, this new concept of literature ensured, via an (invisible) line separating works of genius and the "sea of popular writing," that there was not too much social mobility to threaten bourgeois distinction. 
Even as literature undoubtedly performed this cultural work for a rising bourgeoisie, this concept emerged from the biopolitical discourse on genius that I have traced in this chapter, and this discourse is different than, and not reducible to, the logic of class conflict stressed by Guillory. ${ }^{51}$ Or, to put this another way, the bourgeoisie drew upon a biopolitical logic of genius more expansive than bourgeois class interests. The difficulty of collapsing the biopolitical logic of genius into bourgeois class interests becomes evident in both William Godwin's reflections on genius and literature in The Enquirer (I797) and Wordsworth's further reflections on deluges and genius in the I805 Prelude. Both accounts contested the bourgeois cultural monopoly on literature central to Guillory's account: Godwin, by presenting literature as that which produces geniuses able to destroy the bourgeois order, and Wordsworth, by connecting genius and literature to what we would now describe as "Anthropocene" ecological concerns.

Godwin's attacks in Enquiry Concerning Political Justice (I793) on all institutions, especially those of property, marriage, and law, make it difficult to describe him as an advocate of bourgeois interests. The Enquirer continued some of those reflections via a shift in both genre and assumptions about reading. Where Political Justice employed the genre of the philosophical system, Godwin described The Enquirer as a paratactic series of essays based on "experiment and observation" and on conversations, rather than a "system" resulting from principles and deductive argument. ${ }^{52}$ This new literary form encouraged Godwin to focus on a problem he had not engaged in Political Justice, namely, how to educate necessarily dependent individualsthat is, children - such that they could become the rational, free subjects at which Political Justice had aimed. To solve this kind of problem, Godwin turned, in the opening essays of The Enquirer, to the topic of genius.

The first three essays of The Enquirer represent a precise, albeit largely implicit, engagement with the mid-eighteenth-century genius debate. In the book's first essay, entitled "Of Awakening the Mind," Godwin considered the importance of innate differences among humans, contending that though "children bring some qualities ... into the world with them," education is nevertheless more important than these innate qualities in establishing the capacities of the individual. ${ }^{53}$ Godwin also assumed, like earlier contributors to the genius debate, that the point of analyzing the nature and causes of genius was to determine how to maximize the number of individuals with great talent in different fields and that increasing the number of geniuses facilitated social progress. However, where earlier authors frequently linked genius to progress through the medium of commerce, Godwin argued that geniuses directly reformed society. He wrote 
that "the affairs of man in society are not of so simple a texture, that they require only common talents to guide them," for "tyranny grows up by a kind of necessity of nature." The complicated affairs of men in society also required that "men of genius . . . rise up, to show their brethren that these evils [of tyranny], though familiar, are not therefore the less dreadful" (Io) and to reveal how to reform social institutions (IO-II). The genius can do this because genius itself is characterized by that same capacity-namely, "a spirit of prying observation and incessant curiosity" (I6) - that enables social reform. Godwin's geniuses do not require the invisible hand of commerce to coordinate their activities into a progressive unitary movement but are instead themselves the points at which potential coordination becomes visible and can be directed.

This redefinition of genius leads into Godwin's third and fourth essays, both entitled "Of the Sources of Genius." In the first of these paired essays, Godwin revived the botanical-agricultural image of the earlier genius debate, contending that the "talents of the mind, like the herbs of the ground, seem to distribute themselves at random" (29). Part of the task of the genius was to subject the emergence of talent in society to "rules" and "system" (30), so that the incidence of genius could be maximized. ${ }^{54}$ This meant, in part, reforming educational institutions, so that more individuals developed that "spirit of prying observation and incessant curiosity" that characterized geniuses. (And for this reason, the topic of genius is not simply a theme treated in The Enquirer but is the primary topic and the telos of the book as a whole.) The key to producing geniuses through education is to keep the forming mind "ductile," rather than producing that mental transformation that characterizes most current forms of education, in which "what was at first cartilage, gradually becomes bone"-that is "stiff, unmanageable and unimpressible" (I7).

Godwin claimed that current modes of education - and, more generally, the current order of society and especially its class divisions-were directed against mental plasticity. As a consequence, Godwin contended, "the present order of society . . . is the great slaughter-house of genius and of mind" (I7). Where Thomas Gray's earlier image of poverty implicitly encouraged readers to make an imaginary survey of England to consider how many would-be Miltons had been muted, Godwin made such a survey explicit. "If a man could go through the island of Great Britain," Godwin wrote,

and discover the secrets of every heart ... how much genius, what a profusion of talent, would offer themselves to his observation? In one place he would discover an embryo politician, in another a philosopher, in a third a 
poet. There is no benefit that can be conferred upon the human race, the seeds and materials of which would not present themselves to his view. Yet the infinite majority of these are destined to be swept away by the remorseless hand of oblivion, and to remain to all future ages as if they had never been. . . Centuries perhaps will glide away, and pine in want of those benefits, which seemed ready to burst from their bud and gladden the human race. (286)

As in the case of the earlier genius debate, Godwin's imaginary survey encouraged readers to imagine technologies or techniques that could make a wide and deep survey throughout the polity and hence capture would-be geniuses on a surface before they were slaughtered by an oppressive class system. ${ }^{55}$

For Godwin, what he called "literature" provided both the image for and a key mechanism of this surface. This is in part because, for Godwin, literature provided the template for the genius him- or herself. For Godwin, the "prying observation and incessant curiosity" of the genius enables what we might call, somewhat anachronistically, an "optimized" use of mental resources. Thus, Godwin wrote, "the chief point of difference between the man of talent and the man without, consists in the different ways in which their minds are employed during the same interval. They are obliged, let us suppose, to walk from Temple-Bar to Hyde-ParkCorner." The dull man goes straight from point A to point B, has few thoughts along the way, and does not look around him. The man of talent, by contrast, "gives full scope to his imagination. . . . He enters into nice calculations. . . He makes a thousand new and admirable combinations" (32). Literature provides the paradigm for this optimizing mental activity of the man of talent, for books "gratify and excite our curiosity in innumerable ways. They force us to reflect. They hurry us from point to point. They present direct ideas of various kinds, and they suggest indirect ones." Literature-exemplified by Godwin with authors such as Thomson, Milton, Gray, Pope, and classical Greek and Latin authors-enables a mind to "becom[e] ductile, susceptible to every impression" (33). ${ }^{56}$ Reading literature transforms what Godwin describes as an uncultivated mental wilderness into a "regulat[ed] mind" (49). ${ }^{57}$

Literature is also a key element of a surface, or medium, that extends the effects of genius throughout a single polity and the world more generally, though more in the way of invisible gas than an invisible hand. Godwin contended that he "can guess very nearly what [he] should have been, if 
Epictetus had not bequested to us his Morals, or Seneca his Consolations." But, he continues,

I cannot tell what I should have been, if Shakespear or Milton had not written. The poorest peasant in the remotest corner of England, is probably a different man from what he would have been but for these authors. Every man who is changed from what he was by the perusal of their works, communicates a portion of the inspiration all around him. It passes from man to man, till it influences the whole mass. I cannot tell that the wisest mandarin now living in China, is not indebted for part of his energy and sagacity to the writings of Milton and Shakespear, even though it should happen that he never heard of their names. (I40)

Because literature is, for Godwin, a technology of mental optimizationthat is, a means by which the mind indirectly learns how to regulate itself more generally - its effects are spread by all the actions of those who read literature and allow it to perform its work of mental optimization on themselves.

Precisely because Godwin developed his image of literature by reconfiguring the earlier genius debate, literature emerged in his text as something other than a form of cultural capital that advanced the class interests of the bourgeoisie, as in Guillory's account. For Godwin, literature was a sediment of human collective intelligence that, in reflexive Romantic fashion, deepened human collective intelligence because of its indirectness, that is, its capacity to enable unexpected connections between places. Hence, rather than confirming bourgeois readers in a sense of aristocratlike exclusivity, literature facilitated the emergence of "men of genius" who "show[ed] their brethren" that the evils of tyranny, "though familiar, are not therefore the less dreadful." 58

The connection that Wordsworth made between literature and the genius debate also drove him beyond the narrow realm of class interests, in this case toward an ecocritical horizon. From the perspective of his later Prelude, Wordsworth's worries in the 1800 Preface to Lyrical Ballads about the potential loss of works of literary geniuses turned out to be simply a special case of a more general worry about the loss of works of genius in all fields (that is, the arts and sciences). Moreover, Wordsworth's fear of metaphorical apocalypse in the Preface to Lyrical Ballads - the "deluge" of novels, sickly and stupid German tragedies, and stories in verse-turned out to be simply a pale reflection of his fear of real deluges, which threatened not only works of genius in all fields but all human works. In the 
"Arab Dream" section of the I80s Prelude, for example, Wordsworth's narrator suggested that neither the printing press nor the category of literature could guarantee the survival of works of genius in the face of a worldwide natural disaster, such as a flood, which contemporary geologists suggested had occurred in the past and might again occur in the future. ${ }^{59}$ While the narrator of The Prelude suggested that the human species would likely survive such a natural disaster, he was convinced that works of genius, and human works in general, would not:

But all the meditations of mankind,

Yea, all the adamantine holds of truth

By reason built, or passion ...

The consecrated works of bard and sage,

...

Where would they be? ${ }^{60}$

In the face of worldwide natural disaster, works of genius are no more durable than any other kinds of works, leading the narrator of The Prelude to despair that the mind had no "element" - that is, nothing with the eternal persistence of air or light—“to stamp her image on" (I54; 1. 45). Wordsworth's worry about the loss of human works, in other words, was restricted neither to literary works, nor to national context, nor even to the valued category of genius. Instead, Wordsworth's worry encompassed the global population of humans and their works and focused on the embodied relationship among humans, their natural environments, and the media by means of which they preserved their works.

Just as Malthus's reflections on population depended for their force on the imagination of an expanding swell of humans that encircled the globe, Wordsworth's worries about the loss of all human works depended upon the imagination of disasters that would engulf not simply this or that national population or literature but the entire global population of the human species. Since literature depends upon the medium of print, humans would be as powerless to preserve its canon in the event of such global catastrophe as they would artistic productions in any other medium. Yet what literature could do-or, at least what Wordsworth sought to achieve within that instance of literature which was The Prelude-was to make such global loss thinkable and affectively pressing. Wordsworth accomplished this by treating his literary text as a sort of gathering place, which linked the biblical Flood and its tremendous importance for the European literary tradition with those geological sciences of Wordsworth's day that proposed the possibility of a new deluge or other form of ecological disaster. 
Such a gathering place enabled Wordsworth, in Godwin's terms, to present "direct ideas of various kinds" and to suggest "indirect ones." This in turn enabled Wordsworth to formulate worries about the fate of human works in the face of a global ecological disaster that would destroy the works produced by past populations, impact all current populations of the world, and, as a consequence, affect future populations as well. From this perspective, both Godwin and Wordsworth indeed suggested a narrowing of the concept of literature from its earlier capacious inclusion of most kinds of printed texts to solely those texts that employ the combination of directness and indirectness described by Godwin. Yet both authors also linked this narrowed concept of literature to future states-the rational, classless society of the future, in Godwin's case, and global ecological devastation, which respects no class boundaries, in Wordsworth's- that cannot be aligned with the functional role of literature in class conflict stressed by Guillory.

Both Godwin's reflections on genius and literature in The Enquirer and Wordsworth's worry in The Prelude about the durability of the works of humans emphasize that though the modern, restricted concept of literature may have been co-opted for the purposes of class conflict, the basic concepts of genius and literature emerged from a crucible of aspirations and worries focused on populations and their embodied dynamics, rather than classes and their social dynamics. This intrinsic link between genius and population was evident in Petty's political arithmetic, but it is equally present in Wordsworth's earlier discussion of works of genius in the Preface to Lyrical Ballads. As Guillory notes, Wordsworth worries in the Preface about how to save works of genius from a literary deluge of inferior works. Yet that literary deluge is itself enabled by what Wordsworth describes as "the encreasing accumulation of men"- that is, an increasing population. This in turn underscores the extent to which the double worry of "overlooking" associated with genius in the eighteenth century - the Elegy's worry of overlooking would-be geniuses and Wordsworth's worry of overlooking what had earlier been recognized as genius — only became possible through the imagination of populations characterized by complex internal dynamics. Petty had seen the increase of population, combined with the creation of surfaces capable of tracking and cultivating populations, primarily as grounds for hope: the possibility of more labor, more wealth, more genius. Gray and Wordsworth — and Thomas Malthus, in a different register-understood that these positive aspirations of regulation and maximization were not thinkable, or at least not affectively moving, unless they were surrounded and illuminated by negative possibilities, that is, images of what might be lost. 


\section{Conclusion}

As I hope has been clear, my argument is not that an autonomous eighteenthcentury form of biopolitics that first emerged around Petty's new science of political arithmetic provides the explanatory context for discussions of genius in literary texts. Rather, I have argued that these subsequent discussions of genius were essential to the more general development of the logic of biopolitics itself. Discussions of genius were important to the development of this logic in several ways. The genius debate, for example, linked biopolitical regulation to a principle of individual uniqueness, and it connected positive aspirations for regulation, such as Petty's desire to maximize genius, to negative, even apocalyptic, alternatives. Understanding these discussions of genius as part of biopolitical discourse also helps us see the latter as encompassing more than simply those clearly biological aspects of collective living stressed by Michel Foucault ("health, hygiene, birthrate, life expectancy, race . . ."). Finally, understanding discussions of maximization and loss of genius as biopolitical presents us with an image of the effects of literary texts, such as Gray's Elegy, different from that described by Guillory: Instead of functioning just, or primarily, as a place of "rest" in the midst of a field of social competition, the Elegy encouraged intense imaginative surveys of population and national territory.

Though there is not necessarily a disjunctive relationship between Guillory's sociological perspective and the biopolitical perspective that I have outlined here, these two perspectives also cannot be simply correlated or combined. The difficulty of coordinating or combining biopolitical and sociological perspectives is a function of the different object of each: Biopolitics focuses on populations, while a sociological perspective focuses on social conflicts, tensions, and forces. The latter are important for population technologies because social conflicts, tensions, and forces in essence constitute key elements of the milieu within which population technologies are employed. There is also no doubt that the appreciation of genius (that is, "taste") functioned in the eighteenth century as a marker of cultural capital and hence served the interests of a bourgeoisie that sought to establish forms of cultural value in place of the hereditary capital provided by aristocratic birth. Yet the discourse on genius, in both its prose and poetic forms, also encouraged the imagination of populations and institutions that could locate and harness differences among individuals in a population. Though this logic can at times be exploited by a social logic of distinction, it fundamentally differs from this latter. Gray's Elegy, for example, indeed likely served the purposes of upward social mobility for a 
specific form of bourgeoisie. However, by means of its abstract image of gifted noble poor, it also facilitated the logic of biopolitics by encouraging the imagination of population, and this latter operates on terrain quite different from the social space within which the dynamics of class play out. As the Elegy highlights through its images of mute Miltons, submerged gems, and inaccessible blooming flowers, the imagination of population meant the thought of an internally differentiated multitude and illuminated possible futures of that multitude through images of radiant gain and lightengulfing loss. As Godwin illustrated in his image of status quo-destroying "men of genius," and Wordsworth underscored in his yearning for a fundamental "element" capable of withstanding global natural catastrophes, the biopolitical logic that connects the discourses of genius and literature could lead authors beyond, or below, the class logic of society and toward concepts of nature that were not simply ideological fronts for "naturalizing" social hierarchies but were rather the thought of a quasi-elemental source of difference from which variation, new qualities, and transformation perpetually emerge.

As I noted in my introduction to this book, literary critics have tended to approach biopolitics as a form of politics even more nefarious and pernicious than class conflict. My suggestion that eighteenth- and earlynineteenth-century concepts of genius and literature emerged from a biopolitical matrix may thus seem like even more bad news, in the sense that this account would provide even more reason to remain ambivalent about or perhaps outright dismissive of these concepts. However, this is not the conclusion that I draw from the account I have developed here. Rather, I see in this account-and especially in Godwin's and Wordsworth's reformulations of the connection between genius and literaturegrounds for both hope and for a rethinking of the redemptive potential of literature. Both Godwin and Wordsworth suggest that it is in and through literature that one can approach populations as entities that have capacities for creating new norms, and the goal of the chapters that follow is to describe some of the means by which Romantic literature sought to accomplish this task. 